\title{
Novel copper(I) complex of 2,5-Bis(2-pyridyl)phosphole: Synthesis, Characterization, Catalytic Activity and DFT Calculations
}

Jeremy Guaramato ${ }^{\mathrm{a}}$, Franmerly Fuentes ${ }^{\mathrm{a}}$, Rocio Rivera ${ }^{\mathrm{a}}$, Deivi Oliveros ${ }^{\mathrm{b}}$, José R. Mora ${ }^{\mathrm{b}}$, Andreas Reiber ${ }^{\mathrm{c}}$, Edward Ávila $^{\mathrm{d}}$, Yomaira Otero ${ }^{\mathrm{a}, \mathrm{e} *}$, Juan M. Garcia-Garfido $^{\mathrm{f} *}$

a Instituto Venezolano de Investigaciones Científicas (IVIC), Centro de Química, Caracas 1020-A, Venezuela.

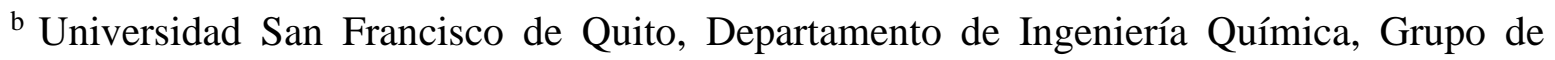
Química Computacional y Teórica (QCT), Quito, Ecuador.

c Universidad de los Andes, Facultad de Ciencias, Departamento de Química, Bogotá, Colombia.

${ }^{\text {d }}$ Universidad Yachay Tech, Escuela de Química e Ingenierías, Grupo de Investigaciones Aplicadas en Materiales y Procesos, Hacienda San José, 100119 Urcuquí, Ecuador.

e Pontificia Universidad Católica del Ecuador, Facultad de Ciencias Exactas y Naturales, Departamento de Química, Quito, Ecuador.

${ }^{\mathrm{f}}$ Universidad de Santiago de Chile, Departamento de Física, Universidad de Santiago de Chile, Santiago de Chile, Chile.

*Corresponding authors: Juan M. Garcia-Garfido, e-mail: juanmanuelgarfido@ gmail.com, juan.garcia.g@usach.cl; Yomaira Otero, e-mail: yomaira@gmail.com, ye.otero@puce.edu.ec.

\section{Abstract}


A novel copper(I) complex containing 2,5-bis(2-pyridyl)-1-phenylphosphole (1a) ligands, $\left[\mathrm{CuCl}\left\{k^{1}(\mathrm{P})-\mathbf{1 a}\right\}\left\{k^{2}(\mathrm{P}, \mathrm{N})-\mathbf{1 a}\right\}\right]$ (2a), has been synthesized and fully characterized by structural and spectroscopic methods. X-ray crystallographic study revealed that copper(I) complex presents a structure with pseudo tetrahedral geometry of formula $\left[\mathrm{CuCl}\left\{k^{1}(\mathrm{P})-\right.\right.$ 1a $\left.\}\left\{k^{2}(\mathrm{P}, \mathrm{N})-1 \mathbf{a}\right\}\right]$. In solution, 1a show a hemilabile behavior giving rise a dynamic equilibrium between four-coordinate $\left[\operatorname{CuCl}\left\{k^{1}(\mathrm{P})-1 \mathrm{a}\right\}\left\{k^{2}(\mathrm{P}, \mathrm{N})-\mathbf{1 a}\right\}\right]$ (2a) and threecoordinate $\left[\mathrm{CuCl}\left\{k^{1}(\mathrm{P})-\mathbf{1 a}\right\}_{2}\right] \quad\left(\mathbf{2 a}^{\prime}\right)$ complexes. Along with previously reported $\left[\mathrm{CuCl}\left\{k^{1}(\mathrm{P})-\mathbf{1 b}\right\}_{2}\right]$ (2b, being $\mathbf{1 b}=2,5$-bis(2-thienyl)-1-phenylphosphole), catalytic potential of copper(I) complex 2a was tested in the synthesis of propargylamines and 1,4-substituted 1,2,3-triazoles via three-component reactions. DFT calculations have been performed to explain both dynamic equilibrium in solution and catalytic activity of $\mathbf{2 a}$ and $\mathbf{2} \mathbf{b}$ complexes.

\section{Introduction}

Phospholes are five membered P-heterocyclic derivatives that show a rich coordination chemistry. They act as $\sigma$-donor ligand by using of the lone pair on phosphorus atom, $\pi$-donor ligand through of the dienic system, $[1,2]$ and even, as polydentate ligand by introduction of pyridine, oxazoline, isoquinoline and amino-N type donor on the skeleton of phosphole.[38] Phosphole ligands with specific electronic and steric properties can be achieved by modification of the substituents at the $\mathrm{C}$-atoms or at the $\mathrm{P}$-atoms of the phosphole ring. For instance, the incorporation of aromatic substituents in 2,5-positions of ring creates an extended $\pi$-conjugated diene system which decrease the hyper-conjugation with the exocyclic P-R bond, reducing the aromaticity and increase $\sigma$-donor ability of phosphole.[9] Thus, phospholes have been used as ligands for transition metal complexes in different fields such as catalysis [10], material science [11,12] and bioinorganic chemistry $[13,14]$. 
Phospholes 2,5-disubstituted by pyridine (1a) and thiophene (1b) were prepared by Réau et al. through Fagan-Nugent [15] method which is based on an oxidative coupling between corresponding 1,7-functionalized diynes and zirconocene followed by treatment with dihalide phosphine compounds $\mathrm{RPX}_{2}(\mathrm{X}=\mathrm{Cl}$ or $\mathrm{Br}$ ) (Figure 1).[7,16] These $\pi$-conjugated phospholes have been used on the development of multifunctional materials for OLED devices,[17] in particular, 2,5-bis(2-pyridyl)-1-phenylphosphole (1a) exhibits a quirky bridging coordination mode of the phosphole $\mathrm{P}$ center offering dimeric metal complexes; among which, some $\mathrm{Cu}(\mathrm{I})$ dimers have been employed as templates for a variety of chromophores that are $\pi$-stacked into nanosized assemblies.[18]

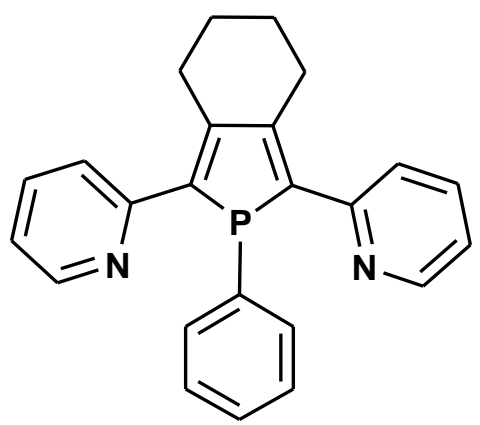

$1 \mathbf{a}$

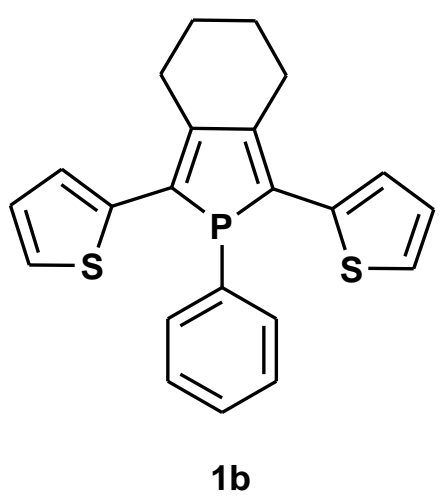

$1 b$

Figure 1. 2,5-bis(2-pyridyl)-1-phenylphosphole (1a) and 2,5-bis(2-thienyl)-1phenylphosphole (1b).

Although, the applications of phospholes in homogeneous catalysis are recognized since early 1970s, the use of 2,5-disustituted phosphole ligands in catalysis has poorly been explored.[10,19-21] Recently, we evaluated the catalytic activity of trigonal copper(I) complex $\left[\mathrm{CuCl}\left\{\kappa^{1}(\mathrm{P})-\mathbf{1 b}\right\}_{2}\right](\mathbf{2 b})$ in the synthesis of propargylamines via $\mathrm{A}^{3}$-coupling reactions of aldehyde, amine and alkyne.[19] We are interested on the propargylamines since these are used as precursors and versatile building blocks for the preparation of various 
nitrogen-containing heterocyclic compounds as well as key intermediates for the synthesis of biologically active pharmaceuticals and natural products. [22-25] Furthermore, some propargylamines have been used for the treatment of neuropsychiatric disorders such as Parkinson's and Alzheimer's disease. [26-28]

$\left[\mathrm{CuCl}\left\{\kappa^{1}(\mathrm{P})-\mathbf{1 b}\right\}_{2}\right](\mathbf{2 b})$ showed to be highly efficient to catalyze $\mathrm{A}^{3}$-coupling reactions to synthetize propargylamine derivaties.[19] Catalyst $\mathbf{2 b}$ is air and moisture stable, and thus either purified reagents or glovebox were not required for carry out the catalytic reactions, and it operated with low loading and in absence of solvents. Catalytic performance of $\mathbf{2 b}$ has encouraged us to explore the synthesis and catalytic activity of an analogous copper(I) complex with 2,5-bis(2-pyridyl)-1-phenylphosphole (1a) ligands. Herein, we show the synthesis and fully characterization of first reported mononuclear copper(I) complex (2a) with 2,5-bis(2-pyridyl)-1-phenylphosphole (1a) ligands. Interestingly, NMR variable temperature experiments reveal that ligand 1a have hemilabile behavior in solution. Similar to $\mathbf{2 b}$, synthetized complex (2a) was tested as catalyst on $\mathrm{A}^{3}$-coupling reactions of aldehyde, amine, and alkyne for preparing propargylamines. Certainly, triazoles are important heterocycles which have tremendous applications in various research fields, including biological science,[29] synthetic organic chemistry,[30,31] medicinal chemistry[32] and material chemistry.[33] We have also tested the catalytic activity of complexes $\mathbf{2 a}$ and $\mathbf{2 b}$ on three-component cyclization of alkyl halides, sodium azide, and alkynes to synthetize 1,4substituted 1,2,3-triazoles. Finally, we performed DFT calculations in order to deep on the understanding of both observed dynamic equilibrium in solution and catalytic activity of catalyst $\mathbf{2 a}$ and $\mathbf{2} \mathbf{b}$ in the studied reactions.

\section{Experimental section}




\section{Materials and methods}

All experiments were performed under an atmosphere of dry argon in the dark using a standard Schlenk technique. The solvents were previously dried and distilled following standard methods prior to use.[34] $\mathrm{PhPBr}_{2}, 2,5$-bis(2-pyridyl)-1-phenylphosphole (1a), 2,5bis(2-thienyl)-1-phenylphosphole (1b) and [ $\left.\mathrm{CuCl}\{2,5 \text {-bis(2-thienyl)-1-phenyl-phosphole }\}_{2}\right]$ (2b) were synthesized according to published procedures. $[3,7,9]{ }^{31} \mathrm{P},{ }^{1} \mathrm{H}$ and ${ }^{13} \mathrm{C}$ NMR spectra were recorded using a Bruker Advance AM 300 spectrometer. IR spectra were recorded on a Shimadsu IRTracer-100 spectrometer using $\mathrm{KBr}$ disks. Mass spectra were acquired on a Thermo Scientific TSQ Quantum Ultra AM Triple Quadrupole mass spectrometer employing the Heated Electrospray Ionization (HESI) technique.

Synthesis of $\left[\mathrm{CuCl}\{\mathbf{1 a}\}_{2}\right](2 a)$

A solution of 2,5-bis(2-pyridyl)-1-phenylphosphole (121.2 mg; $0.17 \mathrm{mmol})$ and $\mathrm{CuCl}(16.3$ mg; $0.17 \mathrm{mmol})$ in $\mathrm{CHCl}_{3}(15 \mathrm{~mL})$ was stirred at $50{ }^{\circ} \mathrm{C}$ under argon for $24 \mathrm{~h}$. The solvent was removed under vacuum and the remaining solid washed on pentane (4 x $10 \mathrm{~mL})$ to give 2a as an orange solid (yield: $100.3 \mathrm{mg} ; 73 \%)$. NMR_ $-{ }^{31} \mathbf{P}\left(\mathbf{3 0 0} \mathbf{M H z}, \mathbf{C D C l}, \mathbf{2 5}{ }^{\circ} \mathbf{C}\right): \delta=7.10$ (s). NMR-1 H $\left(300\right.$ MHz, $\left.\mathbf{C D C l}_{3}, 25{ }^{\circ} \mathbf{C}\right): \delta=8.50\left(\mathrm{~d}, 2 \mathrm{H}, J_{\mathrm{H}}{ }_{-\mathrm{H}}^{5}=3.75 \mathrm{~Hz}, \mathrm{H}^{6}\right) ; 7.70(\mathrm{~m}$,

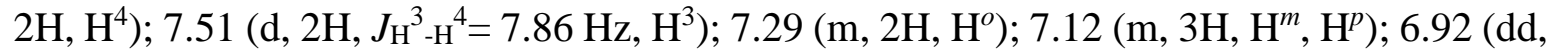
$\left.2 \mathrm{H}, J_{\mathrm{H}}^{5}{ }_{-\mathrm{H}}^{4}=6.18 \mathrm{~Hz}, J_{\mathrm{H}}{ }^{5} \mathrm{P}=11.95 \mathrm{~Hz}, \mathrm{H}^{5}\right) ; 3.21\left(\mathrm{~m}, 2 \mathrm{H}, \mathrm{H}^{9 \mathrm{a}}\right) ; 2.46\left(\mathrm{~m}, 2 \mathrm{H}, \mathrm{H}^{9 \mathrm{~b}}\right) ; 1.64(\mathrm{~m}$, $\left.2 \mathrm{H}, \mathrm{H}^{10 \mathrm{a}}\right) ; 1.47\left(\mathrm{~m}, 2 \mathrm{H}, \mathrm{H}^{10 \mathrm{~b}}\right) . \mathbf{N M R}-{ }^{13} \mathbf{C}\left(\mathbf{3 0 0} \mathbf{M H z}, \mathbf{C D C l}_{3}, 25{ }^{\circ} \mathbf{C}\right): \delta=153.8\left(\mathrm{~s}, \mathrm{C}^{2}\right) ; 150.5$ $\left(\mathrm{s}, \mathrm{C}^{8}\right) ; 149.1\left(\mathrm{~s}, \mathrm{C}^{6}\right) ; 139.9\left(\mathrm{~s}, \mathrm{C}^{7}\right) ; 135.9\left(\mathrm{~s}, \mathrm{C}^{4}\right) ; 133.5\left(\mathrm{~s}, \mathrm{C}^{o}\right) ; 129.9\left(\mathrm{~s}, \mathrm{C}^{p}\right) ; 129.2\left(\mathrm{~s}, \mathrm{C}^{i}\right)$ $128.6\left(\mathrm{~s}, \mathrm{C}^{5}\right) ; 124.2\left(\mathrm{~s}, \mathrm{C}^{3}\right) ; 120.9\left(\mathrm{~s}, \mathrm{C}^{m}\right) ; 29.3\left(\mathrm{~s}, \mathrm{C}^{9}\right) ; 22.5\left(\mathrm{~s}, \mathrm{C}^{10}\right) . \mathbf{I R - F T}\left(\boldsymbol{v}_{\max } \mathbf{c m}^{-\mathbf{1}}\right): 3043$ (ArC-H, st); 2931 and $2862\left(-\mathrm{CH}_{2}-\right.$, st); 1900-1600 (ArC-C); $1582(-\mathrm{C}=\mathrm{N}-$, st $) ; 1462$ and 
$1427(-\mathrm{C}=\mathrm{C}-)$; 1315, 1269, 1096 and $1026(\mathrm{Ar}-\mathrm{H}) ;$ 783, 748 and $698(\mathrm{Ar}-\mathrm{H}) . \mathbf{M S}(\mathbf{M e O H}$, ESI): $799.25\left(\left[\mathrm{C}_{48} \mathrm{H}_{42} \mathrm{~N}_{4} \mathrm{P}_{2} \mathrm{Cu}\right]^{+}\right)$.

General procedure for preparation propargylamines using [CuCl$\left.\{\mathbf{1 a}\}_{2}\right](\mathbf{2 a})$ catalyst.

A seal tube containing a stirrer bar was charged with aldehyde (3.0 mmol), amine ( $3.3 \mathrm{mmol})$ and alkyne (4.5 mmol) and the catalyst $\left[\mathrm{CuCl}\{\mathbf{1 a}\}_{2}\right]$ (2a) (2.6 mg, $\left.0.003 \mathrm{mmol}, 0.5 \mathrm{~mol} \%\right)$. The mixture was stirred at $100{ }^{\circ} \mathrm{C}$ for $1.5 \mathrm{~h}$, cooled, extracted with ether $(3 \times 5 \mathrm{~mL})$ and dried over $\mathrm{MgSO}_{4}$. The mixture was filtrated, concentrated ( ${ }^{1} \mathrm{H}-\mathrm{NMR}$ spectroscopy showed quantitative conversion of aldehyde) and the residue was purified by flash chromatography on silica gel using a hexane/EtOAc mixture as eluent. The corresponding propargylamines (3a-d) (see Table 2) were obtained as yellow oil. All the products were known compounds and were characterized by comparison of their spectroscopic data with those described in the literature.[19]

General procedure for preparation 1,4-disubstituted 1,2,3-triazoles using [CuCl\{2,5disubtituted-1-phenyl-phosphole $\left.\}_{2}\right](\mathbf{2 a}$ and $\mathbf{2 b})$ catalysts.

A seal tube containing a stirrer bar was charged with alkyl halide ( $3.0 \mathrm{mmol}), \mathrm{NaN}_{3}$ (3.3 mmol), alkyne (3.0 mmol), $\mathrm{H}_{2} \mathrm{O}(1 \mathrm{~mL})$ and the catalyst $(0.5 \mathrm{~mol} \% \mathrm{Cu})$. The mixture was stirred at $80^{\circ} \mathrm{C}$ for $5 \mathrm{~h}$. After the reaction was completed, the resulting mixture was extracted with EtOAc $(3 \times 3 \mathrm{~mL})$. The collected organic phases were dried with anhydrous $\mathrm{Na}_{2} \mathrm{SO}_{4}$ and the solvent was removed under vacuum to give the corresponding triazole, the product was further purified by flash chromatography on silica gel using a hexane/EtOAc mixture as eluent.

1-benzyl-4-phenyl-1 H-1,2,3-triazole (4a): $\mathbf{N M R}-{ }^{\mathbf{1}} \mathbf{H}\left(\mathbf{3 0 0} \mathbf{M H z}, \mathbf{C D C l}_{3}, \mathbf{2 5}^{\circ} \mathbf{C}\right): \delta=7.77(\mathrm{~d}$, $\left.2 \mathrm{H}, J_{\mathrm{H}-\mathrm{H}}=7.8 \mathrm{~Hz}, \mathrm{CH}_{\mathrm{Ar}}\right) ; 7.64(\mathrm{~s}, 1 \mathrm{H}, \mathrm{HC}=\mathrm{CPh}) ; 7.44\left(\mathrm{~m}, 2 \mathrm{H}, \mathrm{CH}_{\mathrm{Ar}}\right) ; 7.37\left(\mathrm{~m}, 2 \mathrm{H}, \mathrm{CH}_{\mathrm{Ar}}\right)$; $7.35\left(\mathrm{~m}, 4 \mathrm{H}, \mathrm{CH}_{\mathrm{Ar}}\right) ; 7.30\left(\mathrm{~m}, 3 \mathrm{H}, \mathrm{CH}_{\mathrm{Ar}}\right) ; 7.24\left(\mathrm{~s}, 1 \mathrm{H}, \mathrm{CH}_{\mathrm{Ar}}\right), 5.55\left(\mathrm{~s}, 2 \mathrm{H}, \mathrm{CH}_{2} \mathrm{Ph}\right) . \mathbf{N M R}-{ }^{13} \mathbf{C}$ $\left(\mathbf{7 5} \mathbf{~ M H z}, \mathbf{C D C l}_{3}, \mathbf{2 5}^{\circ} \mathbf{C}\right): \delta=54.2,119.5,125.7,128.0,128.1,128.7,128.7,129.1,130.5$, 134.7, 148.2.

1-[(2-bromo) benzyl]-4-phenyl-1H-1,2,3-triazole (4b): NMR-1 ${ }^{1} \mathbf{H} \quad\left(300 \mathrm{MHz}, \mathbf{C D C l}_{3}\right.$, $\left.\mathbf{2 5}^{\circ} \mathbf{C}\right): \delta=7.80\left(\mathrm{~d}, 2 \mathrm{H}, J_{\mathrm{H}-\mathrm{H}}=7.8 \mathrm{~Hz}, \mathrm{CH}_{\mathrm{Ar}}\right) ; 7.77(\mathrm{~s}, 1 \mathrm{H}, \mathrm{HC}=\mathrm{CPh}) ; 7.62\left(\mathrm{~d}, 2 \mathrm{H}, J_{\mathrm{H}-\mathrm{H}}=8 \mathrm{~Hz}\right.$, 
$\left.\mathrm{CH}_{\mathrm{Ar}}\right) ; 7,39\left(\mathrm{~m}, 2 \mathrm{H}, \mathrm{CH}_{\mathrm{Ar}}\right) ; 7.30\left(\mathrm{~m}, 2 \mathrm{H}, \mathrm{CH}_{\mathrm{Ar}}\right) ;$ 7,26 (m, 2H, $\left.\mathrm{CH}_{\mathrm{Ar}}\right) ; 5,70\left(\mathrm{~s}, 2 \mathrm{H}, \mathrm{CH}_{2} \mathrm{Ph}\right)$. NMR_ ${ }^{13} \mathbf{C}\left(\mathbf{7 5} \mathbf{M H z}, \mathbf{C D C l}_{3}, \mathbf{2 5}^{\circ} \mathbf{C}\right): \delta=53.8,119.8,123.4,125.7,128.2,128.24,128.8$, $130.2,130.4,130.4,133.2,134.23,148.1$.

1-(1-Benzyl-1H-[1,2,3]triazol-4-yl)-butan-1-ol (4c): NMR-1'H (300 MHz, CDCl3, $\left.25^{\circ} \mathbf{C}\right)$ : $\delta=7.36(\mathrm{~s}, 1 \mathrm{H}, \mathrm{HC}=\mathrm{CPh}) ; 7.31\left(\mathrm{~m}, 3 \mathrm{H}, \mathrm{CH}_{\mathrm{Ar}}\right) ; 7.2\left(\mathrm{~m}, 2 \mathrm{H} ; \mathrm{CH}_{\mathrm{Ar}}\right) ; 5.4\left(\mathrm{~s}, 2 \mathrm{H}, \mathrm{CH}_{2} \mathrm{Ph}\right) ; 4.8$

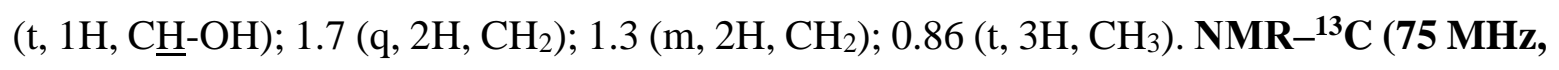
$\left.\mathbf{C D C l}_{3}, \mathbf{2 5}^{\circ} \mathbf{C}\right): \delta=13.7,18.5,39.3,54.0,66.5,127.3,128.6,128.9,134.5$.

3-(1-Benzyl-1H-[1,2,3]triazol-4-yl)-propionitrile (4d): $\mathbf{N M R}-{ }^{\mathbf{1}} \mathbf{H}\left(\mathbf{3 0 0} \mathbf{M H z}, \mathbf{C D C l}_{3}, \mathbf{2 5}^{\circ} \mathbf{C}\right)$ : $\delta=7.3\left(\mathrm{~m}, 3 \mathrm{H}, \mathrm{CH}_{\mathrm{Ar}}\right) ; 7.2\left(\mathrm{~m}, 3 \mathrm{H}, \mathrm{CH}_{\mathrm{Ar}}\right) ; 5.5\left(\left(\mathrm{~s}, 2 \mathrm{H}, \mathrm{CH}_{2} \mathrm{Ph}\right) ; 2.8\left(\mathrm{t}, 2 \mathrm{H}, \mathrm{CH}_{2}\right) ; 2.4(\mathrm{t}, 2 \mathrm{H}\right.$, $\left.\mathrm{CH}_{2}\right) ; 2.0\left(\mathrm{~m}, 2 \mathrm{H}, \mathrm{CH}_{2}\right)$. NMR- ${ }^{13} \mathbf{C}\left(75 \mathbf{M H z}, \mathbf{C D C l} 3, \mathbf{2 5}^{\circ} \mathbf{C}\right): \delta=16.4,24.2,24.7,54.0$, $119.2,127.9,128.7 ; 129.1,134.6$.

$X$-ray crystallography

One single crystal was mounted on a glass fiber and the crystallographic data were collected at 293 (2) K by using an Agilent SuperNova, CrysAlis Pro, Oxford Cryojet, detector Atlas with $\mathrm{Mo} / \mathrm{Cu}$ radiation. The single crystal was always coated in paratone oil once removed from the mother solution. The data merging process was performed using the CrysAlisPro program, Agilent SuperNova CrysAlisPro, Software System, Version 171.37.34. Structure determinations were performed by an intrinsic phasing algorithm with the solving program SHELXT that revealed all the non-hydrogen atoms.

SHELX-2019 program was used to refine the structures by full-matrix least-squares based on F2 with help of graphic interface SHLEXLE. [35-37] Most non-hydrogen atoms were refined with anisotropic displacement parameters. Hydrogen atoms were included in idealized positions and refined with isotropic displacement parameters. In table 1 are shown the crystallographic and refinement details. Reference number CCDC 2044664 contains the supplementary crystallographic data for $\mathbf{2 a}$. These data can be obtained free of charge at www.ccdc.cam.ac.uk/data_request/cif.

Theorical Calculations 
Theoretical calculations were performed by employing the Density Functional Theory (DFT) as implemented in Gaussian 16. The hybrid functional PBEPBE proposed by Adamo et al.[38] was used and in conjunction with the split valence basis set def2svp.[39] The combination PBEPBE/def2svp has demonstrated to describe analogous systems with a considerable accuracy.[40] The optimization process was performed by employing the Berny analytical gradient algorithm and all the convergence criteria was selected as default (Density matrix $=10^{-9}$ a.u., maximum displacement $=0.0018 \AA$, and maximum force $=0.00045$ Hartree/Bohr).

The XRD data of the complexes $\mathbf{2 a}$ and $\mathbf{2 b}$ were used as starting point to perform a rotational barrier scan analysis. The minimum stationary points (conformers) obtained for each complex were used for the analysis of the metal-alkyne $\pi$-interaction in order to gain insight about the catalytic activity of these complexes. A detailed analysis based on the highest occupied molecular orbital (HOMO) and lowest unoccupied molecular orbital (LUMO) was performed for the optimized conformers $\mathbf{2 a}$ and $\mathbf{2} \mathbf{a}$ '. For the characterization of the systems, two electronic descriptors were computed, that is the Wiberg bond's Index (WBI) and perturbation energy E(2). 3-D surface MOs is shown for complexes in the support data. In addition, the Mulliken's charges were computed on the optimized structures of the complexes.

\section{Table 1. Crystallographic Parameters for 2a}

\begin{tabular}{ll}
\hline & \multicolumn{1}{c}{ Crystal data } \\
\hline Chemical formula & $\mathrm{C}_{48} \mathrm{H}_{42} \mathrm{ClCuN} \mathrm{P}_{2}$ \\
$M r$ & 835.78 \\
Crystal system, space group & Monoclinic, $P{ }_{1} / c$ \\
Temperature (K) & 296 \\
$a, b, c(\AA)$ & $19.7882(17), 10.9648(9), 19.2175(17)$ \\
$\beta\left({ }^{\circ}\right)$ & $101.557(9)$ \\
$V\left(\AA^{3}\right)$ & $4085.2(6)$ \\
$Z$ & 4 \\
Radiation type & Mo Ka \\
$\mu\left(\mathrm{mm}^{-1}\right)$ & 0.72 \\
Crystal size (mm) & $0.20 \times 0.15 \times 0.14$ \\
\hline & \multicolumn{1}{c}{ Data collection } \\
\hline Diffractometer & SuperNova, Dual, Cu at zero, Atlas \\
& Multi-scan, CrysAlis PRO 1.171.38.43 (Rigaku Oxford Diffraction, 2015) \\
Absorption correction & Empirical absorption correction using spherical harmonics, implemented \\
$T_{\text {min }}, T_{\text {max }}$ & in SCALE3 ABSPACK scaling algorithm. \\
& $0.464,1.000$
\end{tabular}




\begin{tabular}{ll}
$\begin{array}{l}\text { No. of measured, independent, } \\
\text { and observed }[I>2 \sigma(I)]\end{array}$ & $55986,9464,6693$ \\
reflections & 0.062 \\
$\begin{array}{l}R_{\text {int }} \\
(\sin \theta / \lambda) \max (\AA-1)\end{array}$ & 0.675 \\
\hline \multicolumn{2}{c}{ Refinement } \\
\hline R[F2 $>2 \sigma(\mathrm{F} 2)], \mathrm{wR}(\mathrm{F} 2), \mathrm{S}$ & $0.052,0.160,1.09$ \\
No. of reflections & 9464 \\
No. of parameters & 515 \\
H-atom treatment & $\mathrm{H}$ atoms treated by a mixture of independent and constrained refinement \\
$\Delta \rho_{\max }, \Delta \rho_{\min }\left(\mathrm{e} \AA^{-3}\right)$ & $0.64-0.57$ \\
\hline
\end{tabular}

\section{Results and discussion}

\section{Synthesis and characterization}

The new complex $\left[\mathrm{CuCl}\{\mathbf{1 a}\}_{2}\right]$ was obtained employing the synthetic method previously reported for the similar complexes $\left[\mathrm{CuX}\{2,5 \text {-disubtituted-1-phenyl-phosphole }\}_{2}\right](\mathrm{X}=\mathrm{Cl}$, I).[3,41] Thus, two equivalent of 2,5-bis(2-pyridyl)-1-phenyl-phosphole (1a) react with one equivalent of $\mathrm{CuCl}$ in chloroform at $50{ }^{\circ} \mathrm{C}$ for $24 \mathrm{~h}$ to give $\left[\mathrm{CuCl}\{\mathbf{1 a}\}_{2}\right]$ (2a) (Scheme 1). Complex 2a was isolated in good yield as an air stable orange solid (89\% yield) and resulted stable in different organic solvents such as $\mathrm{CH}_{2} \mathrm{Cl}_{2}, \mathrm{CHCl}_{3}, \mathrm{H}_{2} \mathrm{O}$, DMSO and hexane. Its IR spectrum showed bands corresponding to the main functional groups of 1a $(\mathrm{ArC}-\mathrm{H}$ at 3043 , $-\mathrm{C}=\mathrm{N}-$ at 1582 and $-\mathrm{C}=\mathrm{C}-$ at 1462 and 1427) but shifted respect to free ligand which is related with its coordination to the metal center (see figure S1 in SI). ESI-MS spectrum displays a peak of high intensity at $\mathrm{m} / \mathrm{z} 799.25$, corresponding to the molecular ion $\left[\mathrm{C}_{48} \mathrm{H}_{42} \mathrm{~N}_{4} \mathrm{P}_{2} \mathrm{Cu}\right]^{+}$which indicates the presence of two phosphole ligands to copper center (see Figure S2 in SI).

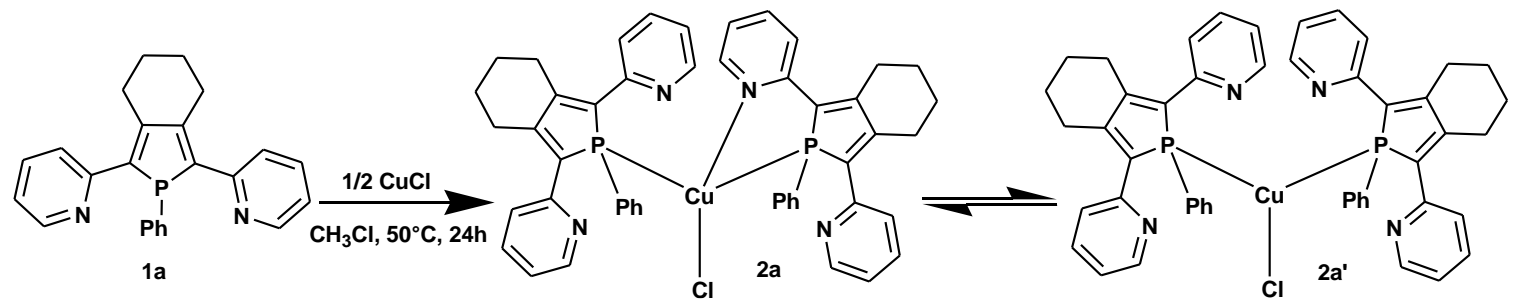

Scheme 1. Synthesis of $\left[\mathrm{CuCl}\{\mathbf{1 a}\}_{2}\right](\mathbf{2 a})$ and its hemilabile behavior in solution for give 2a'.

The ${ }^{31} \mathrm{P},{ }^{1} \mathrm{H}$ and ${ }^{13} \mathrm{C}$ chemical shift variation of each signal with respect to those of the free ligand $(\Delta \delta)$ was used as a parameter to deduce the binding mode of phosphole ligands to the metal (see Figure S3 and S4 in SI). ${ }^{31} \mathrm{P}\left\{{ }^{1} \mathrm{H}\right\}$ NMR spectrum at RT exhibits a signal shifted to 
high-field with respect to the free phosphole $(7.10 \mathrm{ppm})$ which reveals the coordination of phosphole ligands to the copper center. ${ }^{1} \mathrm{H}$ and ${ }^{13} \mathrm{C}\left\{{ }^{1} \mathrm{H}\right\}$ NMR spectra showed very small differences compared to those of the free ligand suggesting a symmetric $\kappa^{1}(\mathrm{P})$-coordination of the two phosphole ligands. Thus, NMR data at RT are consistent with a trigonal threecoordinate cooper(I) complex similar to $\left[\mathrm{Cu}\{2,5 \text {-bis(2-thienyl)-1-phenyl-phosphole }\}_{2} \mathrm{Cl}\right]$ (2b) previously reported,[3] wherein the two phosphole ligands are $\kappa^{1}(P)$-coordinated.

\section{$X$-ray diffraction analysis}

Crystals of complex 2a, suitable for an X-ray diffraction analysis, were obtained by slow evaporation in a dichloromethane solution. XRD analysis showed that molecular structure of 2a consists of a $\mathrm{Cu}(\mathrm{I})$ ion surrounded by one chlorine ligand and two ligands $1 \mathrm{a}$ wherein one acting as a $k^{1}-\mathrm{P}$ monodentate ligand and another acting as a $k^{2}-\mathrm{P}, \mathrm{N}$ chelate ligand (Figure 2). Complex 2a, that crystallizes in the monoclinic crystalline system and space group P21/c (No. 14), shows a pseudo-tetrahedral geometry around copper atom wherein values of bond angles P1-Cu1-N1, P1-Cu1-N2, P1-Cu1-P2 and N1-Cu1-Cl1 are 83.13(7), 117.77(8), 102.2(2) and 103.82(7), respectively.

Molecular structure of 2a shows that $\mathrm{Cu}-\mathrm{Cl}$ bond length (2.2587(9) $\AA$ ) is slight longer than that observed for complex $\mathbf{2 b}$. The Cu1-N1 (2.123(2) ̊̊) and Cu1-P1 (2.3252(8) $\mathrm{A})$ bonds associated to $\mathrm{P}, \mathrm{N}$-chelate phosphole ligand are similar to those observed in copper(I) dimers featuring polydentate 2,5-bis(2-pyridyl)-1-phenyl-phosphole ligands.[42] Dihedral angle P1-C4-C5-N1 $\left(20.2^{\circ}\right)$ shows the torsion between the phosphole and pyridine rings of the bidentate ligand. Finally, Cu1-P2 (2.2449(8) ̊̊) length corresponding to P-monodentate phosphole is shorter than the of $\mathrm{P}, \mathrm{N}$-chelate phosphole ligand, which is agree with $\kappa^{1}(\mathrm{P})$ phosphole ligands in copper(I) complexes.[3] Thus, XDR analysis reveals unambiguously that as-synthetized compound corresponds to a copper(I) complex with pseudo tetrahedral coordination geometry of the type $\left[\mathrm{CuCl}\left\{k^{1}(\mathrm{P})-\mathbf{1 a}\right\}\left\{k^{2}(\mathrm{P}, \mathrm{N})-\mathbf{1 a}\right\}\right]$ instead a trigonal planar, as expected according to NMR data at RT. 


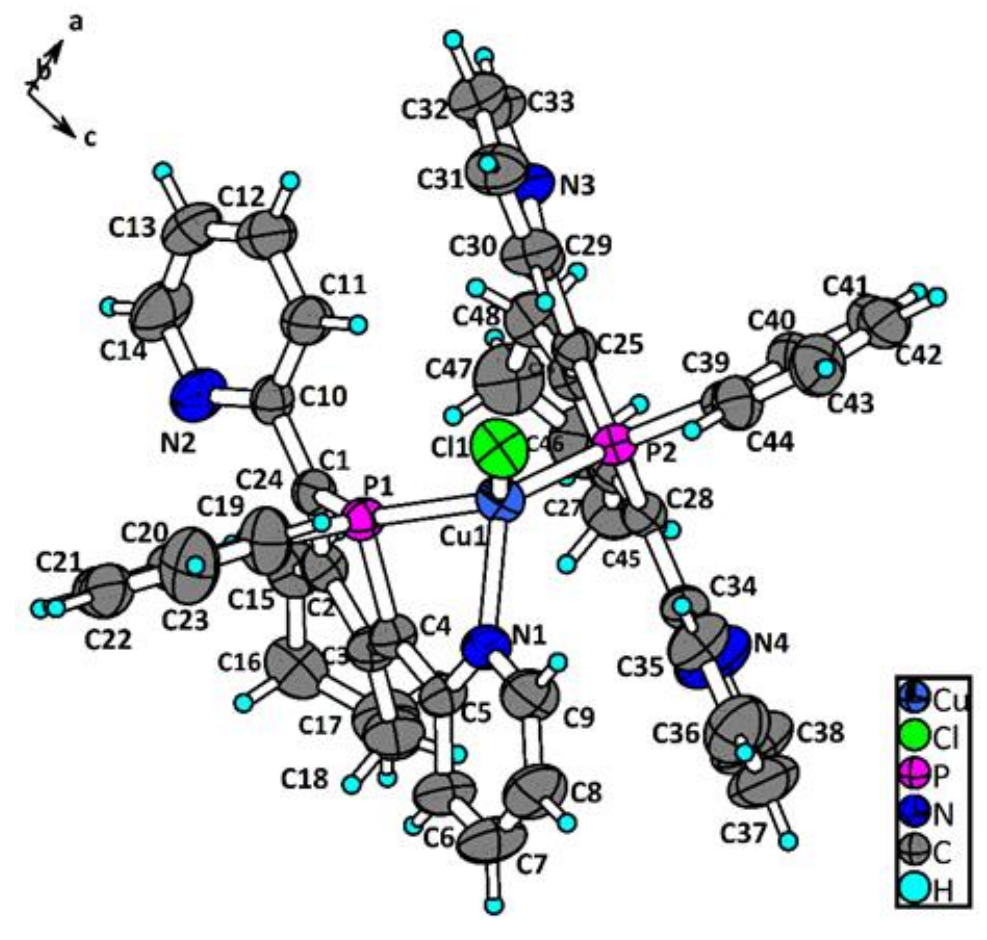

Figure 2. Diagram ORTEP of 2a, showing $50 \%$ probability ellipsoids, and its atom-numbering. Selected bond lengths $(\AA)$ and bond angles (deg): Cu1-N1 2.123 (2), Cu1-P2 2.2449 (8), Cu1-P1 2.3252 (8), Cu1-Cl1 2.2587 (9), N1-C5 1.359 (4) N1-C9 1.335 (5) N2 - C10 1.330 (4), N2-C14 1.337 (5), N3-C29 1.353 (4), N3-C33 1.326 (5), N4-C34 1.348 (5), N4-C38 1.362 (7), Cl1-Cu1-P1 121.82 (3), Cl1-Cu1-P2 116.90 (3), $\mathrm{Cl1}-\mathrm{Cu} 1-\mathrm{N} 1103.81$ (6), P1-Cu1-P2 110.23 (3), P1-Cu1-N1 81.13 (7), P2-Cu1-N1 117.77 (7), Cu1-P1-C1 139.96 (10), Cu1-P1-C4 93.73 (9), Cu1-P1—C19 114.85 (10), C1-P1—C4 90.77 (12), C1-P1-C19 103.12 (14), C4-P1-C19 101.37 (13), Cu1-P2-C25 112.02 (9), Cu1-P2C28 117.01 (10), Cu1-P2-C39 120.59 (11), C25-P2-C28 91.83 (12), C25-P2-C39 103.33 (13), C28P2-C39 107.54 (14).

\section{Variable-temperature NMR analysis}

Although XRD analysis reveals that 2a has pseudo tetrahedral structure; NMR data at RT are consistent with a trigonal three-coordinate cooper(I) complex. Hence, variable-temperature NMR experiments were performed in order to verify the possible existence of a fluxional behavior in solution. Indeed, ${ }^{31} \mathrm{P}\left\{{ }^{1} \mathrm{H}\right\} \mathrm{NMR}$ at $-30{ }^{\circ} \mathrm{C}$ revealed the appearance of one resonance at $\sim 10.3 \mathrm{ppm}$ along with another broad resonance shifted slightly to lower frequency $(\delta=5.6 \mathrm{ppm})$ in comparison to that observed at RT (Figure 3). Over further cooling, both resonances sharpened and shifted to higher field ( $\delta=9.6$ and $4.4 \mathrm{ppm}$, respectively). On increasing temperature, broad signal at RT shifted slightly to higher field $\left(\delta=\sim 9.8 \mathrm{ppm}\right.$ ) by warming to $80^{\circ} \mathrm{C}$. (Figure 3 ). Meanwhile, ${ }^{1} \mathrm{H}$ NMR measurements over a wide temperature range (from 80 to $-90^{\circ} \mathrm{C}$ ) did not reveal significant changes on the signal 
chemical shifts, nevertheless, a slight broadening of the signals from $-15^{\circ} \mathrm{C}$ is observed (see variable-temperature ${ }^{1} \mathrm{H}$ NMR spectra in SI).
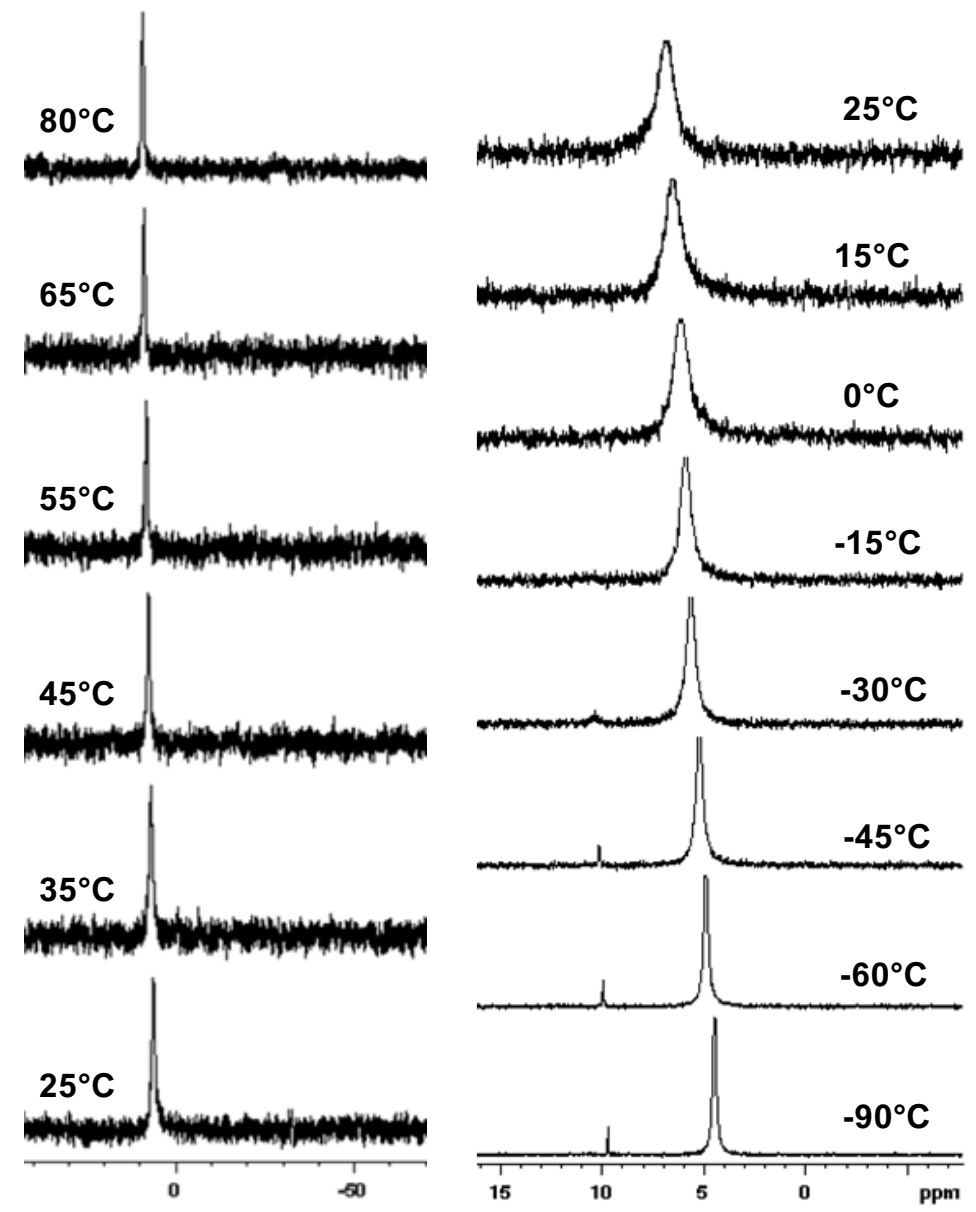

Figure 3. ${ }^{31} \mathrm{P}\left\{{ }^{1} \mathrm{H}\right\}$ NMR spectra of $2 \mathbf{a}$ at variable temperature recorded in DMSO-d 6 (left) and $\mathrm{CD}_{2} \mathrm{Cl}_{2}$ (right).

These NMR data clearly show that complex $\left[\mathrm{CuCl}\left\{k^{1}(\mathrm{P})-\mathbf{1 a}\right\}\left\{k^{2}(\mathrm{P}, \mathrm{N})-\mathbf{1 a}\right\}\right](\mathbf{2 a})$ exhibits a fluxional behavior in solution. It is very likely that this dynamic process is generated by coordination-decoordination of pyridyl groups to give in solution an equilibrium between four-coordinate $\mathbf{2 a}$ and trigonal three-coordinate 2a' complex (Scheme 1). This dynamic process is possibly so fast that the NMR device records the four pyridyl moieties as a single one and, moreover, makes impossible recording the expected $\mathrm{AB}$ resonance pattern in ${ }^{31} \mathrm{P}\left\{{ }^{1} \mathrm{H}\right\}$ NMR spectra for $\mathbf{2 a}$. It is important to highlight that similar hemilabile behavior of ligand 1a has been encountered in both monomeric $\mathrm{Pd}(\mathrm{II}),[21]$ dimeric $\mathrm{Cu}(\mathrm{I})$ complex[43] and triosmium cluster.[44] 


\section{Catalytic study on three-component reactions}

In a recent research work, we have shown that trigonal copper(I)-phosphole complex $\left[\mathrm{CuCl}\left\{k^{1}(\mathrm{P})-\mathbf{1 b}\right\}_{2}\right](\mathbf{2 b})$ is highly efficient catalyst for promoting $\mathrm{A}^{3}$-coupling reactions of aldehyde, amine, and alkyne in absence solvent. We have now examined the catalytic activity of complex 2a in $\mathrm{A}^{3}$-coupling reactions for synthesis of propargylamines. Catalytic potential of 2a was evaluated in the coupling reaction of benzaldehyde, piperidine and phenylacetylene under free-solvent condition (Table 2). A poor conversion was obtained with a catalyst loading of $2 \mathrm{~mol} \%$ at $25^{\circ} \mathrm{C}$ while it was modest by increasing temperature at $50^{\circ} \mathrm{C}$ (Table 2 , entries 1 and 2). Almost total conversion (97\%) into desired product was achieved at $100{ }^{\circ} \mathrm{C}$ within $1 \mathrm{~h}$ using 2 mol\% of $\mathbf{2 a}$ (Table 2, entry 3). A high conversion was achieved by lowering $0.5 \mathrm{~mol} \%$ at $100^{\circ} \mathrm{C}$ after $1 \mathrm{~h}$, but it reduces to $80 \%$ with a loading of $0.1 \mathrm{~mol} \%$ after $5 \mathrm{~h}$ of reaction (Table 2, entries 4 and 5). In terms of TON and TOF (190 and $127 \mathrm{~h}^{-1}$ ), the best catalytic activity of $\mathbf{2} \mathbf{a}$ is achieved in absence of solvent with a catalyst loading of 0.5 mol\% at $100^{\circ} \mathrm{C}$ (Table 2, entry 3 ). Catalyst $2 \mathbf{a}$ shows a good catalytic activity, however, it is lower than found for complex $\mathbf{2 b}$ under optimal reaction condition (Table 2, entry 5; TON 940 and TOF 198 for $\mathbf{2 b}$ ). Interestingly, the difference between catalytic activity of $\mathbf{2 b}$ and 2a result to be greater when reaction was carried out at RT (Table 2, entry 1). Under optimal reaction conditions, catalytic activity of complex $\mathbf{2} \mathbf{a}$ was tested on different combinations of aldehydes, amines and phenylacetylene as depicted in Table 2.

Coupling of aromatic benzaldehyde and aliphatic such as formaldehyde and butyraldehyde using piperidine and pyrrolidine led to corresponding propargylamines $4 \mathbf{a}-\mathbf{d}$ in excellent yields.

Table 2. $\mathrm{A}^{3}$-coupling synthesis of propargylamine catalyzed by $[\operatorname{CuCl}\{2,5$-bis(2thiophenyl)phosphole $\left.\}_{2}\right](2 \mathbf{a})^{a}$
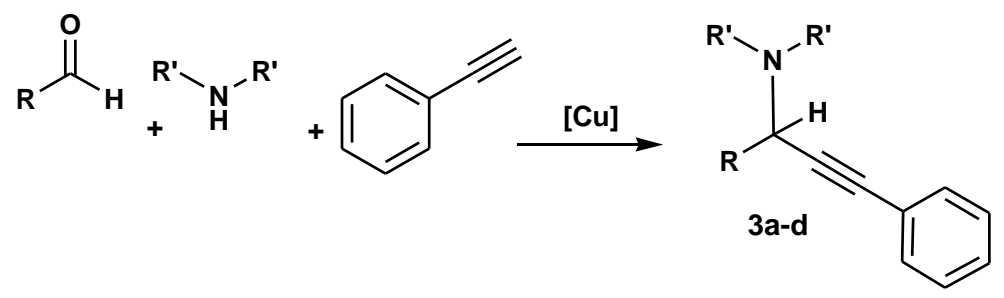
Entry
Aldehyde
Amine
Product
$\underset{(\mathrm{mol} \%)}{[\mathrm{Cu}]}$
Temperature
$\left({ }^{\circ} \mathrm{C}\right)$
(h)
Conversion
$(\%)^{b, f}$ 


\begin{tabular}{cccccccc}
1 & PhCHO & Piperidine & 3d & 2 & 24 & 24 & $7(61)$ \\
2 & PhCHO & Piperidine & 3d & 2 & 50 & 24 & $51(70)$ \\
3 & PhCHO & Piperidine & 3d & 2 & 100 & 1 & $97(99)$ \\
4 & $\mathrm{PhCHO}$ & Piperidine & 3d & 0.5 & 100 & 1.5 & $95(99)$ \\
5 & $\mathrm{PhCHO}$ & Piperidine & 3d & 0.1 & 100 & 5 & $80(94)$ \\
6 & $\mathrm{H}_{2} \mathrm{CO}$ & Piperidine & 3a & 0.5 & 100 & 1.5 & $92^{c, e}$ \\
7 & $\mathrm{CH}_{3}\left(\mathrm{CH}_{2}\right)_{2} \mathrm{CHO}$ & Piperidine & 3b & 0.5 & 100 & 1.5 & $91^{c}$ \\
8 & $\mathrm{PhCHO}$ & Pyrrolidine & 3c & 0.5 & 100 & 1.5 & $90^{c, d}$ \\
9 & $\mathrm{PhCHO}$ & Piperidine & 3d & 0.5 & 100 & 1.5 & $92^{c}$ \\
\hline
\end{tabular}

${ }^{a}$ All the reactions were carried out by using aldehyde $(3 \mathrm{mmol})$, amine $(3.3 \mathrm{mmol})$, phenylacetylene $(4.5$ mmol) and 2a as catalyst in free-solvent conditions. ${ }^{b}$ Conversions were determined by ${ }^{1} \mathrm{H}-\mathrm{NMR}$ spectroscopy of the reaction crude and are average of at least two independent runs. ${ }^{c}$ Isolated yield based on aldehyde. ${ }^{d}$ At $80^{\circ} \mathrm{C} .{ }^{e}$ Using chlorobenzene $(1 \mathrm{~mL})$ as solvent. ${ }^{f}$ Values among parentheses are corresponding to reaction conversion reached using catalyst $\mathbf{2 b}$ under indicated conditions.[19]

Since complexes $\mathbf{2 a}$ and $\mathbf{2 b}$ efficiently drove the $\mathrm{A}^{3}$-coupling reaction of aldehyde, amine and alkyne, we have investigated catalytic potential of $\mathbf{2} \mathbf{a}$ and $\mathbf{2} \mathbf{b}$ on the three-component cyclization of alkyl halides, sodium azide, and alkynes (Table 3). It is one of the sort of transition metal catalyzed multicomponent reaction using in the synthesis of 1,4-disubstituted 1,2,3-triazoles. This version multicomponent constitutes an alternative to the metal-catalyzed azide-alkyne cycloaddition reaction which request the storage and manipulation of organic azides.[45]

Reaction of phenylacetylene, benzyl bromide, and sodium azide was carried out using water as solvent. Both catalysts showed poor catalytic activity when 0.1 mol\% of loading was used (Table 3, entries 1-2 and 7-8). By increasing catalyst loading at $0.5 \mathrm{~mol} \%$, almost total conversion is achieved after 24 hours using catalyst $\mathbf{2 b}$ at RT. High conversion values are reached after 5 hours reaction by increasing temperature at $50^{\circ} \mathrm{C}$ (Table 3 , entries 9 and 10), meanwhile, catalyst $\mathbf{2 a}$ only showed moderate activity under the same condition (Table 2, entry 4). Catalytic activity of $\mathbf{2 a}$ is above $\mathbf{9 0 \%}$ when catalyst loading was increasing at 1 mol\%. Thus, the best activity for catalyst $\mathbf{2 b}$ is achieved under a loading of $0.5 \mathrm{~mol} \%$ at $50^{\circ} \mathrm{C}$ while the highest catalytic activity for $\mathbf{2 a}$ is reached using $1 \mathrm{~mol} \%$. Like for $\mathrm{A}^{3}$-coupling synthesis of propargylamine, catalyst $\mathbf{2 b}$ is more active than $\mathbf{2 a}$ (Table $3, \mathrm{TOF}=38 \mathrm{~h}^{-1}$ for $\mathbf{2 b}$ in entry 10 and $\mathrm{TOF}=19 \mathrm{~h}^{-1}$ for $\mathbf{2 a}$ in entry 10 ).

Table 3. Three-component synthesis of 1,4-disubstituted 1,2,3-triazole catalyzed by [CuCl\{2,5-disubtituted-1-phenylphosphole $\left.\}_{2}\right]\left(2 \mathrm{a}\right.$ and 2b) ${ }^{a}$ 


\begin{tabular}{|c|c|c|c|c|c|c|c|c|}
\hline \multirow[b]{2}{*}{ Entry } & \multirow[b]{2}{*}{ Catalyst } & \multirow{2}{*}{$\begin{array}{l}\mathrm{R} \\
\mathrm{Br}+\boldsymbol{I} \\
\text { Alkyl Bromide }\end{array}$} & \multirow{2}{*}{$\begin{array}{c}\mathrm{NaN}_{3}+\mathrm{R}^{\prime}= \\
\text { Alkyne }\end{array}$} & \multirow[b]{2}{*}{ Product } & [Cu] & 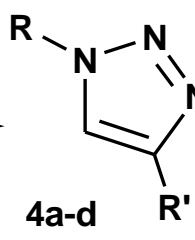 & \multirow[b]{2}{*}{$\begin{array}{c}\text { Time } \\
\text { (h) }\end{array}$} & \multirow[b]{2}{*}{$\begin{array}{c}\text { Conversion } \\
(\%)^{b}\end{array}$} \\
\hline & & & & & $\begin{array}{c}{[\mathrm{Cu}]} \\
(\mathrm{mol} \%)\end{array}$ & $\begin{array}{c}\text { Temperature } \\
\left({ }^{\circ} \mathbf{C}\right)\end{array}$ & & \\
\hline 1 & $\mathbf{2 a}$ & Benzylbromide & Phenylacetylene & $4 \mathbf{a}$ & 0.1 & 25 & 24 & 2 \\
\hline 2 & $\mathbf{2 a}$ & Benzylbromide & Phenylacetylene & $\mathbf{4 a}$ & 0.1 & 50 & 5 & 7 \\
\hline 3 & $\mathbf{2 a}$ & Benzylbromide & Phenylacetylene & $4 \mathbf{a}$ & 0.5 & 25 & 24 & 88 \\
\hline 4 & $\mathbf{2 a}$ & Benzybromide & Phenylacetylene & $4 \mathbf{a}$ & 0.5 & 50 & 5 & 56 \\
\hline 5 & $\mathbf{2 a}$ & Benzylbromide & Phenylacetylene & $4 \mathbf{a}$ & 1 & 50 & 5 & 93 \\
\hline 6 & $2 b$ & Benzy bromide & Phenylacetylene & $\mathbf{4 a}$ & 0.1 & 25 & 24 & 16 \\
\hline 7 & $2 \mathbf{b}$ & Benzylbromide & Phenylacetylene & $4 \mathbf{a}$ & 0.1 & 50 & 5 & 8 \\
\hline 8 & $2 b$ & Benzylbromide & Phenylacetylene & $4 \mathbf{a}$ & 0.5 & 25 & 24 & 98 \\
\hline 9 & $2 \mathbf{b}$ & Benzylbromide & Phenylacetylene & $4 \mathbf{a}$ & 0.5 & 50 & 5 & 95 \\
\hline 10 & $\mathbf{2 a}$ & $\begin{array}{l}\text { 2-bromobenzyl } \\
\text { bromide }\end{array}$ & Phenylacetylene & $4 b$ & 1 & 50 & 5 & 94 \\
\hline 11 & $\mathbf{2 a}$ & Benzylbromide & 5-hexyn-3-ol & $4 c$ & 1 & 50 & 5 & 90 \\
\hline 12 & $\mathbf{2 a}$ & Benzylbromide & 5-hexynenitrile & $4 d$ & 1 & 50 & 5 & 98 \\
\hline 13 & $2 \mathbf{b}$ & $\begin{array}{l}\text { 2-bromobenzyl } \\
\text { bromide }\end{array}$ & Phenylacetylene & $4 b$ & 0.5 & 50 & 5 & 97 \\
\hline 14 & $2 b$ & Benzylbromide & 5-hexyn-3-ol & $4 c$ & 0.5 & 50 & 5 & 99 \\
\hline 15 & $2 \mathbf{b}$ & Benzylbromide & 5-hexynenitrile & 4d & 0.5 & 50 & 5 & 99 \\
\hline 16 & $2 a / 2 b$ & 1-bromobutane & Phenylacetylene & $4 e$ & $1 / 0.5$ & 50 & 24 & $1<$ \\
\hline 17 & $2 \mathbf{a} / 2 \mathbf{b}$ & Benzylbromide & Diphenylacetilene & $4 f$ & $1 / 0.5$ & 50 & 24 & $1<$ \\
\hline
\end{tabular}

${ }^{a}$ All the reactions were carried out by using alkyl halide $(3 \mathrm{mmol})$; sodium azide $(3.3 \mathrm{mmol})$, alkyne $(3$ $\mathrm{mmol}$ ) and catalyst in $1 \mathrm{~mL}$ of $\mathrm{H}_{2} \mathrm{O} \cdot{ }^{b}$ Isolated yield based on alkyl halide.

Catalytic activity of complex $\mathbf{2 a}$ and $\mathbf{2 b}$ was investigated using different combinations of alkyl halides and alkynes under optimal conditions, results are summarized in Table 3. The corresponding 1,4-disubstituted 1,2,3-triazoles were isolated as regiospecific products in excellent yields from the reactions of benzyl halides (benzylbromide and 2-bromo benzylbromide) with phenylacetylene, 5-hexyn-3-ol and 5-hexynenitrile (Table 3, entries 10-15). Catalysts $\mathbf{2 a}$ and $\mathbf{2 b}$ were non-active to catalyze the reactions that involved alkylbromide (1-bromobutane) and internal alkyne such diphenylacetylene due to insolubility of 1-bromobutane in water and the higher steric hindrance of the diphenylacetylene. Catalytic activity of $\mathbf{2} \mathbf{a}$ and $\mathbf{2} \mathbf{b}$ is comparable to those observed for copper(I) complexes containing phosphine ligands.[46-49]

\section{Theoretical calculations}

We performed theoretical calculations with the aim to gain further insight on the formation of copper(I)-phosphole complex 2a' from 2a. A scan analysis was performed for evaluating 
the rotation barriers of the pyridyl groups (Figure 4) in which two minimums were found for copper(I) complex. One conformer labeled as 2a that represents the pseudo tetrahedral complex $\left.\left[\mathrm{CuCl}_{\{} k^{1}(\mathrm{P})-\mathbf{1 a}\right\}\left\{k^{2}(\mathrm{P}, \mathrm{N})-\mathbf{1 a}\right\}\right]$ and another labeled as $\mathbf{2 a}$ ' which depicts to trigonal copper(I) complex $\left[\mathrm{CuCl}\left\{k^{1}(\mathrm{P})-\mathbf{1 a}\right\}_{2}\right]$. Geometrical parameters of the conformers are agreement with structure experimentally determined by XRD analysis, for instance, the distance $\mathrm{Cu}-\mathrm{P}$ in both conformers is between $2.2-2.3 \AA$. The $\mathrm{N}-\mathrm{Cu}$ bond distance is $2.11 \AA$ and dihedral angle $\mathrm{P}-\mathrm{C}-\mathrm{C}-\mathrm{N}$ formed between the phosphole and coordinated pyridine rings is $24.27^{\circ}$. As experimentally observed, conformer $\mathbf{2 a}$ result to be more stable than $\mathbf{2} \mathbf{a}^{\prime}$ by ca. $6.4 \mathrm{kcal} / \mathrm{mol}$. Besides, a maximum was obtained in the scan analysis, which is associated with the arrangement of the pyridyl group in the perpendicular plane to the phosphole ring plane. The maximum of ca. $8.96 \mathrm{kcal} / \mathrm{mol}$ represents the rotation barrier of pyridyl group. This values is close to calculated rotation barriers for quinolyl group in trigonal complexes [CuX(2,5-di(2-quinolyl)-1-phenyl-phosphole) 2$](\mathrm{X}=\mathrm{Cl}, \mathrm{I})$ (ca. 9 kcal/mol).[50] Therefore, energy difference between conformers $\mathbf{2 a}$ and $\mathbf{2 a}$ ' along with relatively low barrier for rotation of pyridyl group would suggest that a fast dynamic equilibrium is favored by suitable orientation of free pyridines as observed in solution. The rotation barrier $(\approx 8 \mathrm{kcal} / \mathrm{mol})$ of the complex $\mathbf{2 b}$ is shown in Figure S18 in SI, and in that case, the most stable conformer corresponds to the trigonal complex in agreement with the experimental results previously reported.[3]

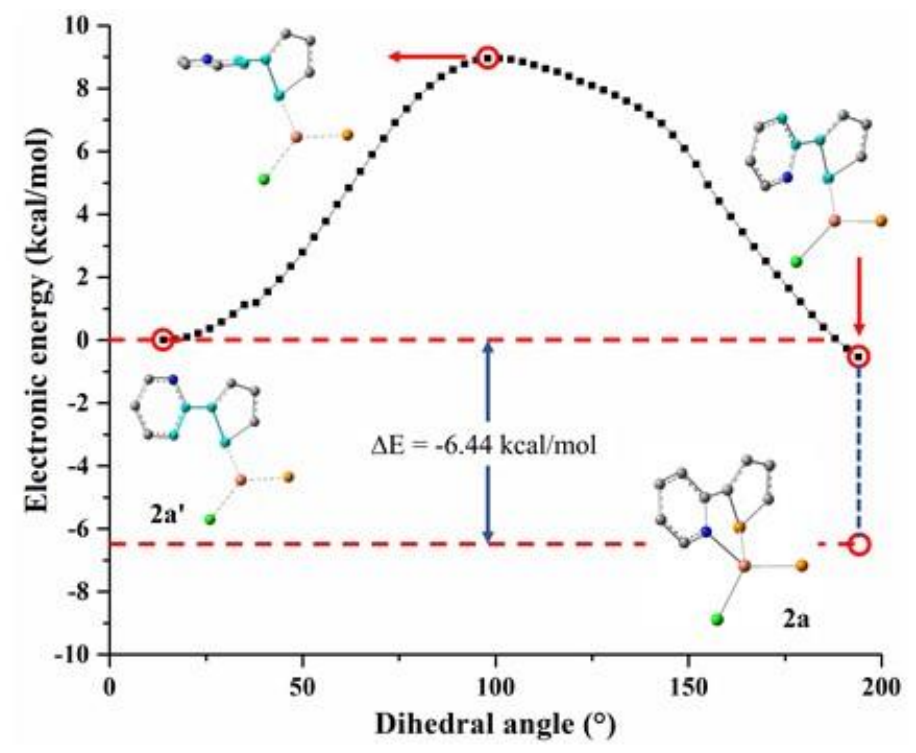


Figure 4. Scan analysis of the rotation barrier energy of pyridyl moiety of $\mathbf{2 a}$.

The donor-acceptor interactions between the ligands and copper center were quantified by the perturbation energy $\mathrm{E}(2)$, which is associated with the delocalization of lone electron pair (LP or $\sigma$ ) or a bonding $\pi$-interaction (BD or $\pi$ ) for ligands as well as antibonding $\left(\sigma^{*}\right.$ ) for the metal center (values are shown in SI, Table S1). Thus, E(2) energies values show the strong donor ligands interaction with copper center in $\mathbf{2} \mathbf{a}^{\prime}\left(\mathrm{E}(2) \approx 88 \mathrm{kcal} / \mathrm{mol}\right.$ for $\sigma(\mathrm{P})-\sigma^{*}(\mathrm{Cu})$ and $\mathrm{E}(2) \approx 77 \mathrm{kcal} / \mathrm{mol}$ for $\left.\sigma(\mathrm{Cl})-\sigma^{*}(\mathrm{Cu})\right)$. But, it is remarkable the fact that $\mathrm{E}(2)$ energies values decrease once pyridyl group is coordinated $\left(\mathrm{E}(2) \approx 54 \mathrm{kcal} / \mathrm{mol}\right.$ for $\sigma(\mathrm{P} 1)-\sigma^{*}(\mathrm{Cu})$ and $\mathrm{E}(2)$ $\left.\approx 67 \mathrm{kcal} / \mathrm{mol} \sigma(\mathrm{Cl})-\sigma^{*}(\mathrm{Cu})\right)$ wherein $\mathrm{E}(2)$ value $(33.32 \mathrm{kcal} / \mathrm{mol})$ for $\sigma(\mathrm{N})-\sigma^{*}(\mathrm{Cu})$ reveals the strength of $\mathrm{N}-\mathrm{Cu}$ coordination (conformer 2a). Analogous trend was found in the calculated Wiberg bond index (WBI) values, i.e. values are lower for $2 \mathbf{a}$ (see values in SI, Table S1). Mulliken atomic charges $(q)$ calculated for $\mathbf{2 a}$ and $\mathbf{2} \mathbf{a}^{\prime}$ indicated that the charge on the copper atom changes from 0.037 au (2a') to 0.084 au (2a) by coordination of pyridyl group.

We have also calculated HOMO and LUMO molecular orbitals for the conformers $\mathbf{2 a}$ and 2a' (see Figure S17 in SI). In the case of 2a', a slight distortion is observed for molecular orbitals of the planar trigonal geometry, in contrast, coordination of pyridyl group (2a) provokes a considerable distortion of the molecular orbitals in the pseudo tetrahedral geometry which are not degenerated. HOMO-LUMO gap energy for the complexes $\mathbf{2 a}$ and 2a' was calculated at -15.73 and $-20.36 \mathrm{kcal} / \mathrm{mol}$, respectively.

Theoretical calculations were also performed to get insight on the reactivity difference between catalysts $\mathbf{2} \mathbf{a}$ and $\mathbf{2} \mathbf{b}$ in studied three-component reactions. In many proposed reaction mechanism, metal-alkyne $\pi$-complex is characterized as an intermediate specie on both $\mathrm{A}^{3}$ coupling synthesis of propargylamine, and synthesis of 1,4-disubstituted 1,2,3-triazol via three-component cyclization of halides, alkynes and sodium azide.[51-53] Therefore, we studied the copper-alkyne $\pi$-interaction (using propyne as model molecule) in $\mathbf{2 a}$ and $\mathbf{2 b}$. Figure 5 shows the energetic profile obtained for the $\pi$-interaction of catalysts with alkyne. Theoretical results indicate that $\mathrm{N}-\mathrm{Cu} \sigma$-bond is likely strong enough for enabling that propyne approaches to metal center, in opposite, the copper-alkyne $\pi$-interaction in catalyst 
2b is energetically favorable by ca. $6.1 \mathrm{kcal} / \mathrm{mol}$. Theoretical evidence explains the higher activity observed for catalyst $\mathbf{2 b}$ respect to $\mathbf{2 a}$, indicating that the trigonal planar geometry eases the copper-alkyne $\pi$-interaction. Indeed, copper-propyne $\pi$-interaction in $2 \mathbf{a}$ is energetically favored (ca. $5.9 \mathrm{kcal} / \mathrm{mol}$ ) by displacement of pyridyl moiety from coordination sphere which result in trigonal copper complex 2a'. This explains the rise of catalytic activity of 2a by increasing the reaction temperature (see in Table 3, entries 1 and 2).

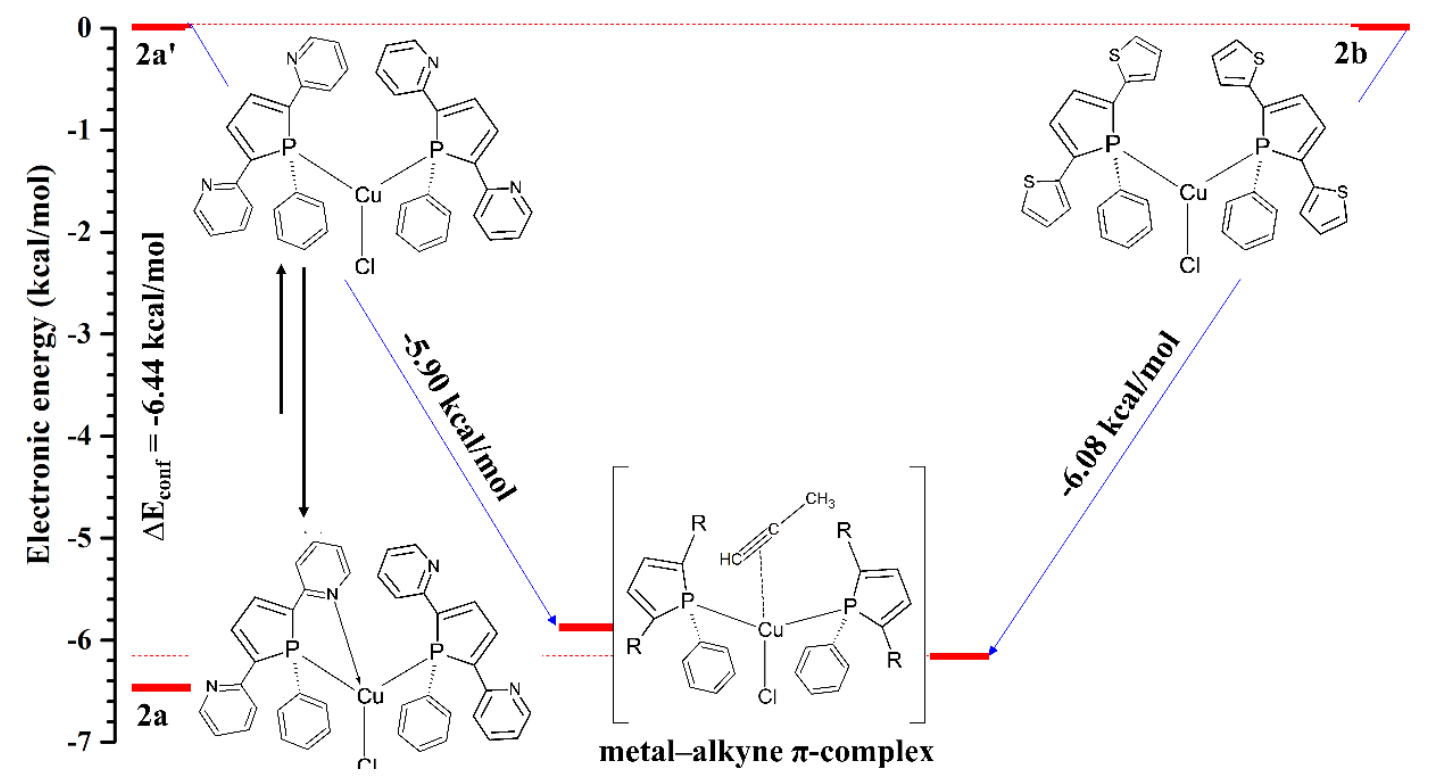

Figure 5. Energetic profile of the copper-alkyne $\pi$-interaction in the catalysts $\mathbf{2 a}$ and $\mathbf{2 b}$.

\section{Conclusions}

In summary, we have synthesized and fully characterized the first mononuclear copper(I) complex $\left[\mathrm{CuCl}\left\{k^{1}(\mathrm{P})-\mathbf{1 a}\right\}\left\{k^{2}(\mathrm{P}, \mathrm{N})-\mathbf{1 a}\right\}\right](\mathbf{1 a}=2,5$-bis(2-pyridyl)-1-phenyl-phosphole (2a). X-ray diffraction analysis revealed unambiguously that 2a presents a pseudo-tetrahedral geometry around of $\mathrm{Cu}(\mathrm{I})$ atom being it is surrounded by one chlorine ligand and two ligands 1a, wherein one exhibits a $k^{1}$-P-coordinationand the other a $k^{2}-\mathrm{P}, \mathrm{N}$ chelate mode. 1a shows a hemilabile behavior changing its coordination mode to give a dynamic equilibrium in solution between four-coordinated $\left[\mathrm{CuCl}\left\{k^{1}(\mathrm{P})-\mathbf{1 a}\right\}\left\{k^{2}(\mathrm{P}, \mathrm{N})-\mathbf{1 a}\right\}\right]$ (2a) and three-coordinate $\left[\mathrm{CuCl}\left\{k^{1}(\mathrm{P})-\mathbf{1 a}\right\}_{2}\right] \quad\left(\mathbf{2} \mathbf{a}^{\prime}\right)$ complex. Theoretical calculations confirmed the experimentally 
observed, pseudo tetrahedral $\mathbf{2 a}$ is more stable than trigonal planar $\mathbf{2 a}$ ' structure, moreover, theoretical data suggest that dynamic equilibrium observed in solution is favored by suitable orientation of free pyridines.

Like complex $\mathbf{2 b}$, complex $\mathbf{2 a}$ results to be active for catalyzing $\mathrm{A}^{3}$-coupling reactions of aldehyde, amine and alkyne in absence solvent. Further, copper(I) complexes $\mathbf{2 a}$ and $\mathbf{2 b}$ showed be efficient to catalyze multicomponent direct synthesis of 1,4-disubstituted 1,2,3triazoles from the reaction of alkynes, organic halides, and $\mathrm{NaN}_{3}$. These complexes are air and moisture stable and hence either purified reagents or glovebox were not required for carry out the catalytic reactions and they operated with low loading. Experimental data showed that catalytic activity of $\mathbf{2} \mathbf{a}$ and $\mathbf{2} \mathbf{b}$ is comparable to that previously observed for copper(I) complexes containing phosphine ligands. However, $\left[\mathrm{CuCl}\left\{\kappa^{1}(\mathrm{P})-\mathbf{1 b}\right\}_{2}\right]$ (2b) showed be more active than $\left[\mathrm{CuCl}\left\{k^{1}(\mathrm{P})-\mathbf{1 a}\right\}\left\{k^{2}(\mathrm{P}, \mathrm{N})-\mathbf{1 a}\right\}\right](\mathbf{2 a})$ for catalyzing both threecomponent synthesis of propargylamines and 1,4-substituted 1,2,3-triazoles. Theoretical calculation indicated that lower activity for $\mathbf{2 a}$ is associated to $\mathrm{N}-\mathrm{Cu} \sigma$-bond of coordinated pyridine which is likely strong enough for enabling the interaction of alkyne with copper center. Theoretical data suggests that the trigonal planar geometry of seems to be a more suitable structure for the copper-alkyne $\pi$-interaction.

Catalytic data, herein showed, allow us to affirm that copper(I) complexes $\mathbf{2 a}$ and $\mathbf{2 b}$ are promising catalysts for promoting activation alkyne reactions. We expect that this research becomes a useful contribution on the development of new homogeneous catalysts.

\section{Acknowledgements}


We thank the Instituto Venezolano de Investigaciones Científicas for financial support (Project $\mathrm{N}^{\circ} 1082$ and 1210). The authors thank Laura Lopez from Universidad de Los Andes, Bogotá-Colombia for her help with the IR-FT spectrum measurement. The authors have used the high-performance computing (HPC) system available in Universidad San Francisco de Quito for the theoretical calculations presented in this work.

\section{Supplementary data}

Supplementary data associated with this article can be found, in the online version.

\section{References}

1. Quin, L. (2005) The Continuing Development of the Chemistry of Phospholes. Current Organic Chemistry, 10 (1), 43-78.

2. Phosphorus-Carbon Heterocyclic Chemistry - 1st Edition.

3. Alfonso, S., González, S., Higuera-Padilla, A.R., Vidal, A., Fernández, M., Taylor, P., Urdanibia, I., Reiber, A., Otero, Y., and Castro, W. (2016) A new complex of copperphosphole. Synthesis, characterization and evaluation of biological activity. Inorganica Chimica Acta, 453, 538-546.

4. Thoumazet, C., Melaimi, M., Ricard, L., Mathey, F., and Le Floch, P. (2003) A cationic 1-(2-methylpyridine)phosphole cymene ruthenium chloride complex as an efficient catalyst in the transfer hydrogenation of ketones. Organometallics, 22 (8), 1580-1581.

5. Sava, X., Marinetti, A., Ricard, L., and Mathey, F. (2002) Optically Active Phospholes: Synthesis and Use as Chiral Precursors for Phosphinidene and Phosphaferrocene Complexes. European Journal of Inorganic Chemistry, 2002 (7), 1657-1665. 
6. Doucet, H., and Brown, J.M. (1997) Synthesis of 1'-(2-diarylphosphino)1naphthyl)isoquinolines; variation of the aryl substituent. Tetrahedron Asymmetry, $\mathbf{8}$ (22), 3775-3784.

7. Hay, C., and Vilain, L. (1999) 2, 5-Di ( 2-pyridyl ) phospholes : model compounds for the engineering of $\mathrm{p}$-conjugated donor - acceptor co-oligomers with a chemically tunable HOMO - LUMO gap. 806 (1), 345-346.

8. Hay, C., Fischmeister, C., Hissler, M., Toupet, L., and Réau, R. (2000) Electropolymerization of $\pi$-conjugated oligomers containing phosphole cores and terminal thienyl moieties: Optical and electronic properties. Angewandte Chemie International Edition, 39 (10), 1812-1815.

9. Hay, C., Hissler, M., Fischmeister, C., Rault-Berthelot, J., Toupet, L., Nyulászi, L., and Réau, R. (2001) Phosphole-containing $\pi$-conjugated systems: From model molecules to polymer films on electrodes. Chemistry - A European Journal, 7 (19), $4222-4236$.

10. Fourmy, K., Nguyen, D.H., Dechy-Cabaret, O., and Gouygou, M. (2015) Phospholebased ligands in catalysis. Catalysis Science and Technology, 5 (9), 4289-4323.

11. Baumgartner, T. (2014) Insights on the design and electron-acceptor properties of conjugated organophosphorus materials. Accounts of Chemical Research, 47 (5), $1613-1622$.

12. Joly, D., Tondelier, D., Deborde, V., Geffroy, B., Hissler, M., and Réau, R. (2010) Phosphole-based $\pi$-conjugated electroluminescent materials for OLEDs. New Journal 
of Chemistry, 34 (8), 1603-1611.

13. S, A.-B., P, T., I, U., W, C., and Y, O. (2018) Studies of the Interaction of Au(I)Phosphole Complexes with DNA and their Relation to Biological Activity. Journal of Medicinal Chemistry and Drug Design, 1 (1), 1-7.

14. Viry, E., Battaglia, E., Deborde, V., Müller, T., Réau, R., Davioud-Charvet, E., and Bagrel, D. (2008) A Sugar-Modified Phosphole Gold Complex with Antiproliferative Properties Acting as a Thioredoxin Reductase Inhibitor in MCF-7 Cells. ChemMedChem, 3 (11), 1667-1670.

15. Am, J. (1988) = 0.207,. Society, (d), 2310-2312.

16. Deborde, Â., Sauthier, M., Guennic, B. Le, and Re, Â. (2001) COMMUNICATIONS A Rare Phosphane Coordination Mode : Dinuclear Palladium ( i ) Complex **. 7870 (1), 228-231.

17. Fave, C., Cho, T.Y., Hissler, M., Chen, C.W., Luh, T.Y., Wu, C.C., and Réau, R. (2003) First examples of organophosphorus-containing materials for light-emitting diodes. Journal of the American Chemical Society, 125 (31), 9254-9255.

18. Nohra, B., Graule, S., Lescop, C., and Réau, R. (2006) Mimicking [2,2]paracyclophane topology: Molecular clips for the coordination-driven cofacial assembly of $\pi$-conjugated systems. Journal of the American Chemical Society, 128 (11), 3520-3521.

19. Cammarata, J.R., Rivera, R., Fuentes, F., Otero, Y., Ocando-Mavárez, E., Arce, A., and Garcia, J.M. (2017) Single and double A 3 -coupling (aldehyde-amine-alkyne) 
reaction catalyzed by an air stable copper(I)-phosphole complex. Tetrahedron Letters, 58, 4078-4081.

20. De Souza, R.F., Bernardo-Gusmão, K., Cunha, G.A., Loup, C., Leca, F., and Réau, R. (2004) Ethylene dimerization into 1-butene using 2-pyridylphosphole nickel catalysts. Journal of Catalysis, 226 (1), 235-239.

21. Sauthier, M., Leca, F., Toupet, L., and Réau, R. (2002) Palladium complexes of a novel family of P,N-chelates, the 2-(2-pyridyl)phospholes: Synthesis, structural characterization, and catalytic activity for olefin/CO copolymerization. Organometallics, 21 (8), 1591-1602.

22. Liu, Y. (2013) Recent advances on diversity oriented heterocycle synthesis via multicomponent tandem reactions based on A3 coupling. Arkivoc, 2014 (1), 1-20.

23. Vessally, E. (2016) A new avenue to the synthesis of highly substituted pyrroles: Synthesis from N-propargylamines. RSC Advances, 6 (22), 18619-18631.

24. Vessally, E., Edjlali, L., Hosseinian, A., Bekhradnia, A., and Esrafili, M.D. (2016) Novel routes to quinoline derivatives from N-propargylamines. RSC Advances, 6 (55), 49730-49746.

25. Matsuda, I., Sakakibara, J., and Nagashima, H. (1991) A Novel Approach to $\alpha$ Silylmethylene- $\beta$-lactams via Rh-catalyzed Silylcarbonylation of Propargylamine Derivatives. Tetrahedron Letters, 32 (50), 7431-7434.

26. Baranyi, M., Porceddu, P.F., Gölöncsér, F., Kulcsár, S., Otrokocsi, L., Kittel, Á., Pinna, A., Frau, L., Huleatt, P.B., Khoo, M.L., Chai, C.L.L., Dunkel, P., Mátyus, P., 
Morelli, M., and Sperlágh, B. (2016) Novel (Hetero)arylalkenyl propargylamine compounds are protective in toxin-induced models of Parkinson's disease. Molecular Neurodegeneration, 11 (1), 1-21.

27. Yu, P.H., Davis, B.A., and Boulton, A.A. (1992) Aliphatic Propargylamines: Potent, Selective, Irreversible Monoamine Oxidase B Inhibitors. Journal of Medicinal Chemistry, 35 (20), 3705-3713.

28. Chen, J.J., Swope, D.M., and Dashtipour, K. (2007) Comprehensive review of rasagiline, a second-generation monoamine oxidase inhibitor, for the treatment of Parkinson's Disease. Clinical Therapeutics, 29 (9), 1825-1849.

29. Alvarez, R., Velázquez, S., San-Félix, A., Aquaro, S., De Clercq, E., Perno, C.F., Karlsson, A., Balzarini, J., and Camarasa, M.J. (1994) 1,2,3-Triazole-[2',5'-Bis-O(tert-butyldimethylsilyl)- $\beta$-D-ribofuranosyl]-3'-spiro-5"-(4"-amino-1",2"-oxathiole 2",2"-dioxide) (TSAO) Analogs: Synthesis and Anti-HIV-1 Activity. Journal of Medicinal Chemistry, 37 (24), 4185-4194.

30. Dai, Q., Gao, W., Liu, D., Kapes, L.M., and Zhang, X. (2006) Triazole-based monophosphine ligands for palladium-catalyzed cross-coupling reactions of aryl chlorides. Journal of Organic Chemistry, 71 (10), 3928-3934.

31. Wacharasindhu, S., Bardhan, S., Wan, Z.K., Tabei, K., and Mansour, T.S. (2009) Oxidative palladium catalysis in S NAr reactions leading to heteroaryl ethers from pyridotriazol-1-yloxy heterocycles with aryl boronic acids. Journal of the American Chemical Society, 131 (12), 4174-4175. 
32. Tron, G.C., Pirali, T., Billington, R.A., Canonico, P.L., Sorba, G., and Genazzani, A.A. (2008) Click chemistry reactions in medicinal chemistry: Applications of the 1,3dipolar cycloaddition between azides and alkynes. Medicinal Research Reviews, 28 (2), 278-308.

33. Nandivada, H., Jiang, X., and Lahann, J. (2007) Click chemistry: Versatility and control in the hands of materials scientists. Advanced Materials, 19 (17), 2197-2208.

34. Kieboom, A.P.G. (2010) Purification of Laboratory Chemicals, 3rd edition. D.D. Perrin and W. L. F. Armarego. Pergamon Press, Oxford, 1988, X + 392 pp. ISBN 008-034714-2, Flexicover, Price £37.50. ISBN 0-08-034715-0, Hardcover, Price £75.00. Recueil des Travaux Chimiques des Pays-Bas, 107 (12), 685-685.

35. Sheldrick, G.M. (2008) A short history of SHELX. Acta Crystallographica Section A: Foundations of Crystallography, 64 (1), 112-122.

36. Sheldrick, G.M. (2015) Crystal structure refinement with SHELXL. Acta Crystallographica Section C: Structural Chemistry, 71 (1), 3-8.

37. Hübschle, C.B., Sheldrick, G.M., and Dittrich, B. (2011) ShelXle: A Qt graphical user interface for SHELXL. Journal of Applied Crystallography, 44 (6), 1281-1284.

38. Adamo, C., and Barone, V. (1999) Toward reliable density functional methods without adjustable parameters: The PBE0 model. Journal of Chemical Physics, 110 (13), $6158-6170$.

39. Ernzerhof, M., and Scuseria, G.E. (1999) Assessment of the Perdew-Burke-Ernzerhof exchange-correlation functional. Journal of Chemical Physics, 110 (11), 5029-5036. 
40. Cardozo, C., Mendoza, A., Farías, G., Formiga, A.L.B., Peña, D., Fuentes, F., Arce, A., and Otero, Y. (2019) Synthesis of rhenacyclopentadienes and $\eta 2: \eta 2$-diyne complexes from a labile dirhenium carbonyl and $\pi$-conjugated 1,7-octadiynes: Structural and photophysical characterization. Journal of Organometallic Chemistry, 881, 34-44.

41. Rios, N., Fuentes, F., Oliveros, D., Mora, J.R., Garcia-Garfido, J.M., and Otero, Y. (2021) Synthesis, characterization, and photophysical properties of a new 2,5di(aryl)phosphole derivative and their trigonal copper-phosphole complexes. Journal of Coordination Chemistry, 1-12.

42. Nohra, B., Rodriguez-Sanz, E., Lescop, C., and Réau, R. (2008) Chemistry of bridging phosphanes: Cui dimers bearing 2,5-bis(2-pyridyl)phosphole ligands. Chemistry - A European Journal, 14 (11), 3391-3403.

43. Leca, F., Sauthier, M., Deborde, V., Toupet, L., and Réau, R. (2003) Chemistry of bridging phosphanes: PdI dimers bearing 2,5-dipyridylphosphole ligands. Chemistry - A European Journal, 9 (16), 3785-3795.

44. Published version_Fluxional behaviour of phosphole and phosphine ligands on triosmium clusters.pdf.

45. Herrera, R.P., and Marques-Lopez, E. Multicomponent reactions : concepts and applications for design and synthesis.

46. Kamijo, S., Jin, T., Huo, Z., and Yamamoto, Y. (2004) A One-Pot Procedure for the Regiocontrolled Synthesis of Allyltriazoles via the Pd-Cu Bimetallic Catalyzed Three- 
Component Coupling Reaction of Nonactivated Terminal Alkynes, Allyl Carbonate, and Trimethylsilyl Azide. Journal of Organic Chemistry, 69 (7), 2386-2393.

47. Gonda, Z., and Novák, Z. (2010) Highly active copper-catalysts for azide-alkyne cycloaddition. Dalton Transactions, 39 (3), 726-729.

48. Pérez-Balderas, F., Ortega-Muñoz, M., Morales-Sanfrutos, J., Hernández-Mateo, F., Calvo-Flores, F.G., Calvo-Asín, J.A., Isac-García, J., and Santoyo-González, F. (2003) Multivalent neoglycoconjugates by regiospecific cycloaddition of alkynes and azides using organic-soluble copper catalysts. Organic Letters, 5 (11), 1951-1954.

49. Wang, D., Li, N., Zhao, M., Shi, W., Ma, C., and Chen, B. (2010) Solvent-free synthesis of 1,4-disubstituted 1,2,3-triazoles using a low amount of $\mathrm{Cu}(\mathrm{PPh} 3) 2 \mathrm{NO} 3$ complex. Green Chemistry, 12 (12), 2120-2123.

50. Rios, N., Fuentes, F., Garcia Garfido, J.M., and Otero, Y. (2020) Synthesis, Characterization and Photophysical Properties of a New 2,5-Di(aryl)phosphole Derivative and Their Trigonal Copper-Phosphole Complexes.

51. Peshkov, V.A., Pereshivko, O.P., and Van Der Eycken, E. V. (2012) A walk around the A 3-coupling. Chemical Society Reviews, 41 (10), 3790-3807.

52. Wang, S., Jia, K., Cheng, J., Chen, Y., and Yuan, Y. (2017) Dual roles of substituted thiourea as reductant and ligand in CuAAC reaction. Tetrahedron Letters, 58 (38), $3717-3721$.

53. Himo, F., Lovell, T., Hilgraf, R., Rostovtsev, V. V., Noodleman, L., Sharpless, K.B., and Fokin, V. V. (2005) Copper(I)-catalyzed synthesis of azoles. DFT study predicts 
unprecedented reactivity and intermediates. Journal of the American Chemical Society, 127 (1), 210-216. 